\title{
LIMITAÇÕES ORÇAMENTÁRIAS: DESAFIOS À ASSISTÊNCIA ESTUDANTIL DA UNB EM TEMPOS DE PANDEMIA
}

\author{
BUDGETARY CONSTRAINTS: CHALLENGES TO UNB'S STUDENT ASSISTANCE \\ IN PANDEMIC TIMES
}

\author{
Carolina Cassia Batista Santos ${ }^{1}$ \\ Patricia Paulino Muniz de Abrantes ${ }^{2}$ \\ Rafael Zonta ${ }^{3}$
}

\begin{abstract}
RESUMO: O objetivo deste artigo é apresentar os retrocessos na implementação de programas da Assistência Estudantil na Universidade de Brasília (UnB), considerando especificamente as limitações orçamentárias impostas à Educação por meio de medidas governamentais que alteram a Constituição Federal de 1988 e estabelecem um teto de gastos orçamentários com a Emenda Constitucional no 95. Serão analisados dados referentes aos anos de 2014 a 2019 e considerado o início do ano de 2020, no qual os impactos da pandemia da Covid-19 impuseram à sociedade uma adaptação nos processos de trabalho e estudo, refletidos no planejamento e execução das políticas de permanência na UnB. O estudo caracteriza-se como pesquisa documental, tendo como instrumentais a análise documental e a observação participante. Os resultados apresentados demonstram uma estagnação do investimento nos programas de assistência estudantil, pois os avanços atingidos nos anos anteriores tornam-se demandas reprimidas.
\end{abstract}

Palavras-chave: Assistência estudantil. Políticas de permanência. Limitações orçamentárias. Educação superior. Covid-19.

ABSTRACT: The objective of this article is to present the setbacks in the implementation of Student Assistance programs at the University of Brasilia (UnB), specifically considering the budget limitations imposed on Education through government measures that alter the Federal Constitution of 1988 and establish a budget spending ceiling with Constitutional Amendment n. 95. Data for the years 2014 to 2019 will be analyzed and the beginning of the year 2020 will be considered, in which the impacts of the pandemic of the Covid-19 virus imposed on society an adaptation in the work and study processes, reflected in the planning and execution of health policies stay at $\mathrm{UnB}$. The study is characterized as documentary research, with documental analysis and observation as instruments. The results presented show a stagnation of investment in student assistance programs, where the setbacks to the advances achieved in previous years are noticeable when there is an increase in pent-up demand.

Key-words: Student assistance. Permanence policies. Budget limitations. College education. Covid-19.

\footnotetext{
${ }^{1}$ Doutora em Ciências Sociais pela Universidade Estadual de Campinas-SP (UNICAMP), Professora Adjunta da Universidade Federal do Amazonas (UFAM) e Vice-líder do Grupo de Pesquisa Inter-Ação/UFAM, carolinacassia@,ufam.edu.br

${ }^{2}$ Bacharel em Serviço Social pela Universidade de Brasília, Especialista em Gestão Pública pela Universidade Estadual do Goiás, Analista Superior da Empresa Brasileira de Infraestrutura Aeroportuária - Infraero, cedida para o Senado Federal, patricia.abrantes@senado.leg.br

3 Bacharel em Administração pela Universidade Anhanguera, Especialista - MBA Executivo em Gestão Empresarial, Mestrando em Economia pela Universidade de Brasília. Servidor técnico-administrativo de nível superior da UnB, rafaelzonta@unb.br
} 


\section{INTRODUÇÃO}

Os processos de expansão, inclusão e democratização da educação superior no Brasil, desenvolvidos no período entre 2007 a 2015, contou com a implementação de políticas de expansão das universidades públicas federais, a criação dos institutos federais e a implementação da lei de cotas sociais, resultando na diversificação do perfil dos estudantes universitários brasileiros.

A importância da discussão da democratização do acesso ao ensino se dá no âmbito histórico da luta por uma educação pública de qualidade para todos, pleiteada por diversos movimentos sociais e entendida como elemento fundamental de uma sociedade democrática. Este fenômeno suscita novos desafios, não apenas aqueles relacionados à qualidade de ensino, mas também os concernentes à permanência e à titulação de estudantes socioeconomicamente vulneráveis.

Foram analisados dados referentes ao período entre os anos de 2014 a 2019, bem como o início do ano de 2020, no qual os impactos da pandemia da Covid-19 impuseram a toda comunidade universitária a adaptação aos processos de trabalho e estudo, refletindo também no planejamento e na execução das políticas de permanência na Universidade de Brasília (UnB).

Neste sentido, o objetivo deste artigo é apresentar os retrocessos na implementação de programas da Assistência Estudantil na UnB, lócus deste estudo, considerando especificamente as limitações orçamentárias impostas à Educação por meio de medidas governamentais que alteram a Constituição Federal de 1988 (CF-88) e estabelecem um teto de gastos orçamentários com a Emenda Constitucional no 95 (EC-95), os quais incidem fortemente nas políticas de permanência das universidades federais brasileiras.

Este artigo é resultado de estudos sobre o desenvolvimento de políticas de permanência na UnB, com ênfase na implementação de programas de assistência estudantil e caracteriza-se como pesquisa documental nos relatórios e pesquisas institucionais. A sistematização da observação participante ocorreu no âmbito do campo de execução dos programas, especificamente, a Diretoria de Desenvolvimento Social do Decanato de Assuntos Comunitários da $\mathrm{UnB}$ - DDS/DAC/UnB. As principais categorias analíticas que dão sustentação teórica à análise são: assistência estudantil, políticas de permanência, limitações orçamentárias, educação superior e pandemia da Covid-19. 


\section{ASSISTÊNCIA ESTUDANTIL COMO DIREITO E COMO POLÍTICA}

A educação como direito social é o fundamento desta discussão. O pressuposto do conhecimento é a igualdade. Essa igualdade pretende que todos os membros da sociedade tenham iguais condições de acesso aos bens trazidos pelo conhecimento, de tal forma que possam participar em termos de escolhas ou concorrência no que uma sociedade considera como significativo e serem bem-sucedidos e reconhecidos como iguais (CURY, 2007, p. 486). O aspecto central aqui destacado se reporta às garantias - não apenas de acesso, mas de permanência e conclusão do processo educacional até a obtenção da titulação pelos discentes socioeconomicamente vulneráveis. Compreendendo a assistência estudantil como um direito de cidadania, articulado à função social da educação.

Para Pereira e Souza (2017, p. 75-78) a política de Assistência Estudantil contribui positivamente quando é vista como um direito e não mera ajuda ou benemérito social, tornandose política pública ao ser pensada e colocada em prática para não ser fomentadora de mecanismos que reforcem dicotomias entre assistência social e educação. As autoras compartilham do paradigma que compreende a assistência social na perspectiva dos direitos e, portanto, pela sua coparticipação no processo de universalização e democratização da Política de Educação. Neste sentido, a Educação cumpre o seu papel transformador, sem concessões às demandas meritocráticas impostas pela lógica mercantil.

No caso da Assistência Estudantil tem-se que considerar que o processo educacional é, por natureza, dinâmico e progressista, no sentido de estimular competências e desempenhos, espírito crítico, participação que não precisam ser competitivos; pelo contrário, deveriam ser colaborativos. O direito de estudar está relacionado ao direito humano de autonomia que constitui o patamar mais elevado de satisfação de necessidades sociais entendidas para além da mera sobrevivência física. (PEREIRA; SOUZA, 2017, p. 75).

Em se tratando dos estudos sobre a assistência estudantil, destacam-se os programas federais de acesso e permanência, que precisam ser problematizados conceitualmente e tratados quanto a sua viabilidade e exequibilidade nas práticas institucionais.

$\mathrm{Na}$ sequência do lançamento do Plano de Reestruturação e Expansão das Universidades Federais (REUNI), em abril de 2007, o Governo Federal pretendendo dar respostas às demandas advindas da Associação Nacional dos Dirigentes das Instituições Federais de Ensino Superior (Andifes) e do Movimento Estudantil, criou o Programa Nacional de Assistência Estudantil (PNAES), por meio da Portaria Normativa do Ministério da Educação (MEC) no 39, de 12/12/2007, considerando a centralidade da assistência estudantil como estratégia de combate às desigualdades sociais e regionais, bem como sua importância para a ampliação e a 
democratização das condições de acesso e permanência dos jovens no ensino superior público federal.

O PNAES estabeleceu suas ações vinculadas ao desenvolvimento das atividades de ensino, pesquisa e extensão, direcionadas aos estudantes matriculados em cursos presenciais de graduação, selecionados, prioritariamente, por critérios socioeconômicos, abrangendo as áreas de moradia, alimentação, transporte, assistência à saúde, inclusão digital, cultura, esporte, creche e apoio pedagógico.

Nessa conjuntura, as universidades federais já apresentavam uma demanda significativa para a assistência estudantil. A III Pesquisa Nacional sobre o "Perfil Socioeconômico e Cultural dos Estudantes de Graduação das Universidades Federais Brasileiras", realizada pelo Fórum Nacional de Pró-reitores de Assuntos Comunitários e Estudantis (Fonaprace), em 2009, apontava que os estudantes pertencentes às Classes C, D e E (renda familiar per capita de até três salários-mínimos) representavam 44\% da amostra. Este percentual sobe para $69 \%$ e $52 \%$ nas regiões Norte e Nordeste, respectivamente. Esses estudantes representavam 36\% na região Centro-Oeste e o mesmo percentual de 34\% tanto na região Sul quanto na região Sudeste do país (ANDIFES, 2011).

A partir de 19/07/2010, o PNAES passa a ser regulamentado pelo Decreto Presidencial no 7.234/2010. As ações a serem desenvolvidas pelo Programa atendem, prioritariamente, estudantes que cursaram a educação básica na rede pública ou com renda familiar per capita de até um salário-mínimo e meio e abrangem as seguintes áreas: moradia estudantil, alimentação, transporte, atenção à saúde, inclusão digital, cultura, esporte, creche; bem como o apoio pedagógico e o acesso, a participação e a aprendizagem de estudantes com deficiência, transtornos globais do desenvolvimento e altas habilidades e superdotação (BRASIL, Decreto $\left.n^{\circ} 7.234 / 2010\right)$.

Com a institucionalização do PNAES evidencia-se sua importância como um mecanismo de redução das desigualdades sociais, no âmbito da Educação Superior, e como um diferencial na prevenção da retenção e da evasão. Da mesma forma, importa destacar o papel das IFES na implementação desse programa, considerando a sua competência em definir critérios e metodologias de seleção e designar equipes de profissionais e gestores que trabalhem diretamente na execução das ações nas instituições.

Em 2016, o Fonaprace apresentou os dados da IV Pesquisa Nacional sobre o Perfil Socioeconômico e Cultural dos Estudantes de Graduação das Universidades Federais Brasileiras de 2014, demonstrando o aspecto de vulnerabilidade socioeconômica desses estudantes e as 
desigualdades de renda, acentuadas pelas desigualdades regionais, além de retratar questões de gênero, raça e etnia (ANDIFES, 2016).

Mais recentemente, foram divulgados os dados da V Pesquisa Nacional sobre o Perfil Socioeconômico e Cultural dos Estudantes de Graduação das Universidades Federais Brasileiras (ANDIFES, 2019), coletados em 2018, a partir dos quais constata-se que 70,2 \% da população discente apresenta renda familiar per capita de até 1,5 salário-mínimo, indicando um aumento das classes D e E nas universidades federais em comparação com os dados levantados nas duas pesquisas anteriores.

O balanço dessa realidade traz o questionamento que, apesar dos avanços advindos com o PNAES, as políticas voltadas para a assistência estudantil ainda são residuais, estabelecidas por meio de programas governamentais, com orçamento insuficiente para cobrir a crescente demanda, assunto a ser tratado no item seguinte. É importante dar ênfase à necessidade da consolidação da assistência estudantil como política pública de Estado.

\section{ORÇAMENTO PÚBLICO PARA EDUCAÇÃO SUPERIOR E SUAS LIMITAÇÕES NA UNB}

Em tempos de desmantelamento do Estado de bem-estar social, com o agressivo avanço do neoliberalismo, o orçamento público mais que um instrumento de planejamento, tornou-se uma ferramenta de cunho político que reflete a correlação de forças sociais e políticas na sociedade (SALVADOR, 2017, p. 428). Sob esta perspectiva, em 15/12/2016 foi aprovada a EC-95, instituindo um novo regime fiscal que passou a limitar o crescimento de investimentos e despesas públicas nos três poderes por vinte anos. Saúde e educação não foram poupadas dos efeitos desta escolha política para diminuir o déficit público. É nesta conjuntura que a UnB desenvolve sua política de assistência estudantil.

A UnB possui uma população que chega a 54.641 mil pessoas habitualmente convivendo na instituição, composta por estudantes, docentes, servidores técnicos e terceirizados, podendo chegar a um número ainda mais expressivo se levar em consideração a circulação e utilização da estrutura dos quatro campi por pesquisadores e pela sociedade. Somente a população de estudantes representa $89,9 \%$ do total (UNB, 2020a).

A administração institucional da UnB pode facilmente assemelhar-se ao de uma cidade de pequeno porte. O que se distingue na administração da universidade, de fato, é a sua missão e finalidade, que consiste em oferecer ensino, pesquisa e extensão de excelência. 
O desprendimento de recursos orçamentários que são da ordem de 1,8 bilhão de reais ano é requisito central para o propósito institucional. A verba destinada à UnB é estabelecida na Lei Orçamentária Anual - LOA, a qual estabelece o Orçamento da União, estima as receitas e fixa as despesas do Governo, em conformidade com o $₫ 2^{\circ}$ do Art. 165 da CF-88. Houve aumentos gradativos nos recursos da LOA entre 2014 e 2019, no entanto, desse montante, cerca de 85\% é vinculado às despesas obrigatórias, como pagamento de pessoal, incluindo aposentados e pensionistas. Essa parcela não é gerida pela UnB, estando ao encargo do Governo Federal. Demais valores referem-se às despesas discricionárias (UNB, 2020).

Ainda, quanto aos dados da UnB sobre recursos financeiros da LOA - dotação inicial (investimento e custeio - discricionária), aponta-se que o recurso disponibilizado pelo Tesouro Nacional para investimento em 2016 foi de R $\$ 47$ milhões; em 2017 reduzido consideravelmente para $\mathrm{R} \$ 24$ milhões. No ano de 2018 foi disponibilizado apenas $\mathbf{R} \$ 8.212$ milhões e, em 2019, $\mathrm{R} \$ 5.183$ milhões, tendo uma variação de $-10,74 \%$, entre 2019 e 2018 . No que se refere ao custeio, em 2016 foi sancionado o valor de R \$216 milhões, enquanto entre os anos de 2017 e 2019 o Governo Federal aprovou $\mathrm{R} \$ 136, \mathrm{R} \$ 137$ e $\mathrm{R} \$ 146$ milhões de reais, respectivamente (UNB, 2020a).

Segundo dados do Relatório de Gestão da Universidade de Brasília, o acréscimo no orçamento geral foi de 3,88\% de 2018 para 2019. Em valores nominais e sem emendas parlamentares, os valores da fonte tesouro da LOA 2019 para despesas discricionárias cresceram 4,4\% em relação ao ano de 2018; para gastos de Outras Despesas Correntes (ODC), o aumento foi de 6,7\%; e, para investimentos, houve uma redução abrupta que diminuiu 36,9\% (UNB, 2020a).

Nota-se que após o impeachment da ex-presidenta Dilma Rousseff, no ano de 2016, e a aprovação da EC-95, proposta pelo seu sucessor, Michel Temer, em dezembro do mesmo ano, houve diminuições desmedidas de recursos financeiros do Tesouro que visavam ao investimento e custeio da UnB, conforme Relatório de apresentação pública do Decanato de Orçamento e Planejamento da UnB - 2019 (p. 7-10).

Cabe ressaltar que no ano de 2019, a UnB, assim como outras Instituições de Ensino Superior (IES), foi afetada pelos cortes e contingenciamento financeiro do governo federal por meio do Ministério da Educação (MEC), que inicialmente justificou a ação por supostamente as universidades apresentarem ações de "balbúrdia"4 e, após manifestos de diversos setores sociais,

\footnotetext{
${ }^{4} \mathrm{O}$ ministro da Educação na época, Abraham Weintraub, ressuscitou a balbúrdia, a palavra. O termo que já saiu da boca de personagens shakespearianos e outros clássicos, e andava um pouco esquecido no meio de tanta "confusão", "alvoroço", "escarcéu" e "zoeira", ganhou força ao ser usado como uma das justificativas para o corte de recursos das federais.
} 
principalmente da educação, o governo federal retrocedeu apontando que o contingenciamento seria para a manutenção dos recursos financeiros, com liberação paulatina. O que não ocorreu, ficando as instituições públicas desguarnecidas até o final do ano de 2019. O bloqueio de recursos pelo governo atingiu $31,4 \%$ do orçamento discricionário da UnB com custeio e investimento, no mesmo ano (UNB, 2020a).

No ano de 2020 a humanidade enfrenta uma emergência em saúde pública, a pandemia infligida pelo vírus SARS COV 2 (causador da Covid-19), que impactou sobremaneira todo o mundo; porém, destacam-se as consequências no Brasil dada a conjuntura política, social e econômica. Tal emergência foi declarada pela Organização Mundial de Saúde - OMS em 30/01/2020, alertando para os altos riscos de contaminação em todos os países do mundo e a necessidade da tomada de providências baseadas em evidências científicas.

O Ministro da Saúde do Brasil em exercício do cargo, naquele momento, Luiz Henrique Mandetta, recepcionou esse alerta emitindo a Portaria no 188 de 03/02/2020, estabelecendo um Centro de Operações de Emergências em Saúde Pública (COE-nCoV) para coordenar nacionalmente as ações de controle e combate à Covid-19. O Congresso Nacional começou a trabalhar na aprovação de leis que pudessem destinar recursos e ferramentas para os estados e municípios enfrentarem a situação. Das legislações aprovadas, destaca-se a Emenda à Constituição no 106/2020, que prevê uso de dinheiro público para medidas econômicas que possam minimizar os efeitos da pandemia, conhecida também como "orçamento de guerra". Foi possível perceber o descompasso entre o posicionamento do Presidente da República Jair Messias Bolsonaro e as ações defendidas pelo então Ministro da Saúde, defensor das diretrizes e orientações divulgadas pela OMS, enquanto o Presidente da República fazia declarações públicas relativizando a pandemia e tentando se isentar de suas responsabilidades como Chefe de Estado.

Este posicionamento presidencial fez com que os estados, os municípios e o Congresso Nacional tomassem o protagonismo nas ações de prevenção e combate à pandemia. Neste sentido, os entes federados adotaram o isolamento social horizontal como uma das principais medidas de contenção da disseminação do vírus.

É neste cenário que as instituições de ensino no Brasil, em todos os níveis, suspenderam suas atividades presenciais e precisaram repensar as formas de realizar suas ações. Na particularidade dos estudantes assistidos pelas políticas de assistência estudantil das universidades públicas

"Universidades que, em vez de procurar melhorar o desempenho acadêmico, estiverem fazendo balbúrdia, terão verbas reduzidas", disse o ministro em entrevista ao Estadão, no dia 30 de abril de 2019. 
federais, coube questionar como estes seriam atendidos nas novas demandas e necessidades emergenciais que a pandemia da Covid-19 impôs as suas realidades em um cenário de limitações orçamentárias, que estagnaram os recursos da assistência estudantil. Todas as ações públicas foram direcionadas para mitigar os efeitos da pandemia tanto na saúde pública quantos os efeitos sociais e econômicos decorrentes dela, isso não seria diferente no âmbito da UnB.

\section{EFEITOS DAS LIMITAÇÕES ORÇAMENTÁRIAS SOBRE A POLÍTICA DE PERMANÊNCIA ESTUDANTIL DA UNB}

A Diretoria de Desenvolvimento Social (DDS) tem a competência de assessorar o Decanato de Assuntos Comunitários (DAC) na coordenação, planejamento, execução, gerenciamento, monitoramento e avaliação dos programas, projetos e ações desenvolvidas no âmbito da Política de Assistência Estudantil da UnB.

Apesar das mudanças ocorridas no campo da assistência estudantil terem início a partir de 2008, quando verbas específicas do Governo Federal foram destinadas diretamente para as ações de assistência estudantil nas universidades federais, direcionadas para um público de estudantes em vulnerabilidade socioeconômica preestabelecido, o corte temporal deste estudo concentra-se no anos de 2014 a 2019, considerando-se o período de impacto orçamentário sobre os programas de assistência estudantil desenvolvidos pela DDS/DAC/UnB com os recursos do PNAES. Da mesma forma, serão consideradas as ações emergenciais do ano de 2020, em decorrência da pandemia da Covid-19.

A Política de Assistência Estudantil desenvolvida pelo DDS/DAC/UnB, direcionada aos estudantes matriculados em cursos de graduação presenciais e pós-graduação (stricto sensu) ${ }^{5}$, está pautada nos preceitos constitucionais e suas ações visam minimizar as desigualdades sociais e econômicas existentes entre os estudantes, o que implica no desenvolvimento de estratégias de inclusão social, democratização do acesso, permanência e formação acadêmica com qualidade, evitando a retenção e a evasão de estudantes em situação de vulnerabilidade social e econômica. A DDS, por meio de edital de avaliação socioeconômica, qualifica estudantes em vulnerabilidade socioeconômica como perfil para acesso aos programas de alimentação, auxílio

\footnotetext{
${ }^{5}$ Ressalta-se que os estudantes de graduação da assistência estudantil são mantidos com os recursos oriundo do PNAES e recursos próprios da UnB, já os estudantes da pós-graduação são mantidos com recursos exclusivos da instituição, pois não são contemplados pelo PNAES.
} 
socioeconômico, moradia estudantil na Casa do Estudante Universitário (CEU), auxílio moradia estudantil, transporte, crechee isenção nos cursos de língua estrangeira na UnB.

Os estudantes socioeconomicamente vulneráveis na UnB são classificados como Participantes dos Programas de Assistência Estudantil (PPAES) ou Não Participantes dos Programas Assistência Estudantil (NPPAES), tal designação pretende romper com estigmas históricos de nomenclaturas anteriormente utilizadas, como "baixa renda", os quais segmentavam os grupos de estudantes por corte de renda.

Aos avanços alcançados agregam-se novas demandas por assistência estudantil, a partir das mudanças de perfil dos estudantes, especialmente pela Lei de Cotas Sociais (Lei no 12.711/2012) implementada na UnB em 2013 e, no mesmo ano, pela adesão ao Sistema de Seleção Unificada/Exame Nacional do Ensino Médio (SiSU/ENEM), tendo como prioridade o desdobramento de recursos financeiros, ampliação do quadro de profissionais e revisão normativa dos programas de gestão da DDS. (SANTOS et al, 2017).

Conforme a Tabela I, abaixo, percebe-se que de 2014 a 2019 houve progressão no número de estudantes participantes dos programas de assistência estudantil (PPAES). Nessa Tabela considera-se uma série histórica de registro da UnB, onde se identifica um crescimento constante ano a ano do número de PPAES, no entanto, entre 2015 e 2016, ocorreu uma variação modesta, mantendo variação comedida até 2018, em relação a 2014. Cabe destacar que todos os PPAES são beneficiários do Programa Bolsa Alimentação, que garante isenção de pagamento de três refeições (café da manhã, almoço e jantar) diárias nos Restaurantes Universitários da $\mathrm{UnB}$.

TABELA I - PARTICIPANTES DA ASSISTÊNCIA ESTUDANTIL UNB

\begin{tabular}{|c|c|c|c|c|c|}
\hline Ano & $\begin{array}{l}\text { Número de } \\
\text { PPAES }\end{array}$ & Variação \% & $\begin{array}{c}\text { Solicitações de } \\
\text { participação }\end{array}$ & Bolsas concedidas & $\begin{array}{l}\text { Demanda } \\
\text { reprimida }\end{array}$ \\
\hline 2013 & 3216 & $23,50 \%$ & --- & --- & --- \\
\hline 2014 & 4182 & $30,04 \%$ & --- & 966 & $\begin{array}{ll}-- \\
--\end{array}$ \\
\hline 2015 & 4816 & $15,16 \%$ & 1377 & 634 & 743 \\
\hline 2016 & 5391 & $11,94 \%$ & 3246 & 575 & 2671 \\
\hline 2017 & 6768 & $25,54 \%$ & 2421 & 1377 & 1044 \\
\hline 2018 & 7294 & $7,8 \%$ & 3855 & 526 & 3329 \\
\hline 2019 & 6455 & $-11,50 \%$ & 4221 & 2566 & 3382 \\
\hline
\end{tabular}

Analisando os dados de solicitações de participação nos demais programas (auxílio socioeconômico, moradia, transporte e creche) em 2016, dos 3246 interessados apenas 575 se 
tornaram beneficiários; no ano de 2017, dos 2421 interessados, 1377 novos beneficiários foram contemplados. Cabe ressaltar que o número de bolsas concedidas em 2017 relaciona-se com o número de estudantes PPAES que se desligaram dos programas por motivos diversos e não pela real ampliação de bolsas e recursos, e considera a demanda de estudantes que, até 2016, eram perfil para o Programa Bolsa Permanência do MEC (PBP/MEC) e passaram a ser absorvidos pelo Programa Auxílio Socioeconômico, causando uma pressão para a ampliação de vagas que pudesse atender a demanda reprimida do PBP/MEC ${ }^{6}$. Em 2018 nota-se um número expressivo de 3855 estudantes vulneráveis em busca da assistência estudantil, que contemplou apenas 526 devido às limitações do repasse do PNAES observadas no Tabela II. A variação de 2019 chegou a ser negativa em relação ao ano anterior, apesar do aumento de contemplados com bolsas, a demanda foi maior que todos os anos anteriores da série histórica.

\section{TABELA II - EXECUÇÃO ORÇAMENTÁRIA DA AÇÃO 4002 (ASSISTÊNCIA ESTUDANTIL - PNAES) 2014 A 2019}

\begin{tabular}{l|c|c|c|c|c|c} 
Ano & $\mathbf{2 0 1 4}$ & $\mathbf{2 0 1 5}$ & $\mathbf{2 0 1 6}$ & $\mathbf{2 0 1 7}$ & $\mathbf{2 0 1 8}$ & $\mathbf{2 0 1 9}$ \\
\hline Valor & $21.616 .053,87$ & $27.516 .618,54$ & $30.886 .439,7$ & $30.654 .030,91$ & $30.980 .370,00$ & $34.137 .849,00$ \\
\hline $\begin{array}{c}\text { Variação } \\
\text { \% }\end{array}$ & --- & $27,30 \%$ & $12,24 \%$ & $-0,75 \%$ & $1,06 \%$ & $10,19 \%$ \\
\multicolumn{2}{l}{ Decanato de Planejamento e Orçamento/UnB (2019) com adaptações feitas pelos autores. }
\end{tabular}

De todo modo, observa-se que, com os cortes orçamentários e financeiros evidenciados na Tabela II, há uma pressão sobre a assistência estudantil em relação à demanda reprimida, especialmente nos anos de 2016, 2018 e 2019. Nos anos de 2017 e 2018 nota-se uma evidente contenção dos recursos destinados à assistência estudantil, pelo montante da Execução Orçamentária da Ação $4002^{7}$ (Assistência ao Estudante de Ensino Superior). A variação proporcional do valor orçamentário do ano de 2014 para 2015 demonstra uma ampliação de 27,30\%; e em 2016 verifica-se um aumento de 12,24\%. Após a aprovação da EC-95, evidenciase uma redução no orçamento da assistência estudantil de $-0,75 \%$, ou seja, o orçamento de 2017 foi negativo em relação a 2016. Em 2018 houve uma ampliação insignificante de 1,06\% e apenas

\footnotetext{
${ }^{6}$ O Programa Bolsa Permanência, criado pela Portaria n ${ }^{\circ} 389$, de 09/05/2013, é um auxílio financeiro que tem por finalidade minimizar as desigualdades sociais, étnico-raciais e contribuir para permanência e diplomação dos estudantes de graduação em situação de vulnerabilidade socioeconômica, a partir de 2017 sofreu alterações que restringiram outros acessos, além de estudantes indígenas e quilombolas.

7 “Para alcançar os objetivos dos programas, o orçamento define as chamadas ações orçamentárias. Elas representam um detalhamento dos programas, por vezes segmentando os trabalhos com bases em linhas específicas para atender as necessidades da sociedade ou até de outros entes da federação.” (BRASIL, 2020).
} 
em 2019 houve uma recuperação do valor de 10,19\%, mas que ainda representa uma estagnação se considerarmos a ampliação da demanda entre os anos de 2015 e 2019, de aproximadamente $306 \%$ e, nesse mesmo período, a ampliação dos recursos pela média foi de aproximadamente $24 \%$, considerando-se as variações negativas.

A análise dos dados expostos acima nos conduz para a interpretação de que os reflexos da EC95 recaem de maneira significativa sobre a Educação Superior, principalmente, quando se observa a redução dos recursos orçamentários destinados à permanência dos estudantes mais vulneráveis. Isso demonstra que, além dos impactos negativos que pressionam a universidade pública à limitação da execução orçamentária, pode ocasionar um efeito negativo, também, em relação à permanência de estudantes que se encontram na condição de demanda reprimida, ou seja, os estudantes não contemplados nos demais programas podem vir a enfrentar processos de retenção ou evasão dos cursos.

\section{ASSISTÊNCIA ESTUDANTIL EM TEMPOS DE PANDEMIA: IMPACTOS NA UNB}

Desde março de 2020 com a suspensão das atividades presenciais na UnB, devido à emergência de saúde pública no Brasil, o DAC, por meio das suas diretorias, procede no auxílio aos estudantes já beneficiários dos programas de assistência estudantil e, também, demais estudantes em vulnerabilidade socioeconômica que buscaram atendimento.

Foi criado um grupo de trabalho para analisar e propor ações com vistas a diminuir a exposição ao contágio da Covid-19, minimizar o impacto do isolamento e distanciamento social, reforçar os acolhimentos psicossociais e oferecer apoios financeiros e tecnológicos.

Além dos esforços da equipe multiprofissional da assistência estudantil para diminuir o impacto da suspensão das atividades presenciais, foram implementadas medidas de biossegurança para os profissionais e para todos os moradores das casas estudantis de graduação e pós-graduação. As ações emergenciais foram executadas por meio de editais, tais como: auxílio transporte emergencial com passagem terrestre (estudantes que retornaram para os estados de origem em tempo de pandemia); auxílio alimentação; inclusão digital; e alunos conectados (chips para celulares MEC). Além destas ações de suporte tecnológico, foi estruturado mais um laboratório de informática na CEU, para suporte às aulas remotas. Em resumo, conforme visualizado na Tabela III, verifica-se que o investimento total foi de $\mathrm{R} \$ 2.195 .919,00$ para os editais emergenciais. 


\section{TABELA III - ESTUDANTES CONTEMPLADOS COM EDITAIS EMERGENCIAIS}

\begin{tabular}{|c|c|c|c|}
\hline Edital emergencial & $\mathrm{N}^{\circ}$. contemplados & valor unitário & valor total \\
\hline Auxílio transporte* & 38 & 110,00 a $1.100,00$ & $15.864,00$ \\
\hline Auxílio alimentação & 3427 & 465,00 & $1.593 .555,00$ \\
\hline Inclusão digital & 391 & $1.500,00$ & $586.500,00$ \\
\hline Alunos conectados** & 559 & --- & --- \\
\hline
\end{tabular}

Para responder às demandas, a UnB remanejou os recursos já aprovados para utilização no PNAES em 2020, inclusive os recursos destinados à abertura de editais para a recepção de novos estudantes, atendendo a comunidade discente que vivenciou os impactos da Covid-19, utilizando o limite da dotação orçamentária. Percebe-se um esforço mediante as dificuldades enfrentadas pelo contingenciamento orçamentário de 2020.

O cenário da pandemia e as medidas adotadas para mitigar os seus efeitos sobre a vida e a saúde dos estudantes, reforçam a importância da assistência estudantil como um mecanismo de acesso aos direitos, devendo ser ampliada para todos que dela necessitarem, especialmente em um momento de emergência de saúde pública. Para além do auxílio financeiro, é fundamental os suportes de acolhimento social e psicológico aos estudantes, sem negligenciar as condições de trabalho e segurança dos profissionais envolvidos.

Há que considerar que as ações apresentadas pela UnB buscam soluções domésticas para minimizar os efeitos da pandemia frente ao negacionismo político do Governo Federal.

Pelo cenário atual de contingenciamento, estima-se uma redução de aproximadamente 1 bilhão de reais dos recursos para as universidades públicas brasileiras em 2021. A ANDIFES trabalha com a previsão de 185 milhões a menos no orçamento destinado ao PNAES. A perspectiva já é desanimadora para toda a comunidade acadêmica e traz um desalento aos estudantes socioeconomicamente vulneráveis, sob o risco de não serem alcançados pela política de assistência estudantil na universidade federal, comprometendo a sua permanência.

\section{CONSIDERAÇÕES FINAIS}


O processo de empobrecimento da sociedade brasileira, nos últimos anos, tem gerado um contingente maior de estudantes com perfil de vulnerabilidade socioeconômica que necessitam ser contemplados pelos programas de assistência estudantil. Num efeito reverso aos objetivos dos PNAES, o aumento da demanda reprimida traz como consequência o abandono e a retenção escolar desses estudantes. Com a análise dos dados coletados para fins deste estudo foi possível constatar que de 2014 até 2019, apesar dos avanços alcançados na política de assistência estudantil da UnB, nota-se um declínio com o congelamento dos recursos. Há uma pressão na demanda que impede o acesso de todos os estudantes que solicitam assistência estudantil, pois os recursos tornam-se insuficientes para cobrir as necessidades postas, gerando novos processos de exclusão.

No cenário de combate à Pandemia da Covid-19, a UnB, que teve atividades presenciais suspensas, refez seu planejamento de atendimento aos estudantes mais vulneráveis, buscando atender às novas demandas, mesmo com todas as limitações orçamentárias: fechou o restaurante universitário, mas disponibilizou auxílio alimentação em pecúnia aos estudantes que comprovaram a necessidade de permanência e refeições no período de suspensão do semestre letivo da UnB; reformulou o atendimento dos estudantes que permanecem morando nas Casas dos Estudantes Universitários da graduação e pós-graduação, com canais de atendimento online, minimizando o contato social; equipamentos de biossegurança, conforme recomendações da OMS, para profissionais e estudantes assistidos pela política. Essas ações têm caráter emergencial e são fundamentais para a manutenção e permanência dos mais vulneráveis na universidade, objetivo das políticas de assistência estudantil.

Considerando os dados identificados na pesquisa e as projeções orçamentárias para 2021, o prognóstico não é positivo, acrescenta-se a isso um projeto de desmonte das universidades públicas e as consequências advindas dos efeitos da pandemia da Covid-19, que ainda perdurarão por anos incidindo sobre a vida e o futuro de diferentes segmentos da sociedade, especialmente, os estudantes socioeconomicamente vulneráveis, refletindo uma política de desmonte de direitos, indo na contramão da perspectiva da assistência estudantil como instrumento de uma educação transformadora.

\section{REFERÊNCIAS}

ANDIFES. Perfil Socioeconômico e Cultural dos Estudantes de Graduação das Universidades Federais Brasileiras. Associação Nacional dos Dirigentes das Instituições Federais de Ensino Superior (ANDIFES), jul. 2011. 
Perfil Socioeconômico e Cultural dos Estudantes de Graduação das Universidades Federais Brasileiras. Associação Nacional dos Dirigentes das Instituições Federais de Ensino Superior (ANDIFES), jul. 2016.

Perfil Socioeconômico e Cultural dos Estudantes de Graduação das Universidades Federais Brasileiras. Associação Nacional dos Dirigentes das Instituições Federais de Ensino Superior (ANDIFES), maio 2019.

BALBÚRDIA do ministro virou inspiração nas faculdades. ESTADÃO, São Paulo. Disponível em: https://www.terra.com.br/noticias/educacao/balburdia-do-ministro-virou-inspiracaonas-faculdades, da91942634610533a2760ac64f6ea667cjozs2x3.html. Acesso em: 01 mar. 2020.

BRASIL. CONSTITUIÇÃO DA REPÚBLICA FEDERATIVA DO BRASIL DE 1988.

Programa de Apoio a Planos de Reestruturação das Universidades Federais. Decreto no 6.096, de 24 de abril de 2007.

Decreto no 7.234, de 19 de julho de 2010.

Lei de cotas. Lei no 12.711, de 29 de agosto de 2012.

Portal transparência. Disponível em:

http://www.portaltransparencia.gov.br/entenda-a-gestao-publica/programas-de-governo. Acesso em: 21 jun. 2020.

CORTES e contingenciamento ameaçam o futuro da universidade. Situação e desafios - um diálogo com a administração superior. UNB NOTÍCIAS, Brasília, 27 de maio de 2019. Disponível em: http://noticias.unb.br/76-institucional/2938-cortes-e-contingenciamentoameacam-futuro-da-universidade. Acesso em: 29 fev. 2020.

CURY, C. R. J. A gestão democrática na escola e o direito à educação. In: RBPAE - v. 23, n. 3, p. 483-495, set./dez. 2007.

MEC deve ter orçamento reduzido em 18,2\% [...]. Tribuna do Norte, Natal. Disponível em: http://www.tribunadonorte.com.br/noticia/mec-deve-ter-ora-amento-de-2021-reduzido-em18-2-e-universidades-podem-perder-r-1-bilha-o/487182. Acesso em: 20 jun. 2020.

PEREIRA, P. A. P.; SOUZA, J. D. A. Assistência Estudantil: direito ou mérito? O Trabalho de Equipes Multidisciplinares na Assistência Estudantil: análise de experiência profissional na UnB. O trabalho das equipes multiprofissionais na educação - 10 anos do grupo de pesquisa TEDis / coordenação Silvia Cristina Yannoulas. Curitiba [PR]: CRV, 2017. p.17-56. DOI $10.24824 / 978854441700.3$

SALVADOR, E. S. O desmonte do financiamento da seguridade social em contexto de ajuste fiscal. Serv. Social e Sociedade, São Paulo, n. 130, p. 426-446, set./dez. 2017. Disponível em: http:/ / www.scielo.br/scielo.php?script=sci_arttext\&pid=S0101-

66282017000300426\&lng=pt\&nrm=iso. Acesso em: 31 out. 2020. https://doi.org/10.1590/0101-6628.117. 
SANTOS, C. C. B, ABRANTES, P. P. M., ZONTA, R. O Trabalho de Equipes Multidisciplinares na Assistência Estudantil: análise de experiência profissional na UnB. $\mathbf{O}$ trabalho das equipes multiprofissionais na educação - 10 anos do grupo de pesquisa TEDis. Coord. Silvia Cristina Yannoulas. Curitiba: CRV, 2017, p.17-56. DOI 10.24824/978854441700.3

UNIVERSIDADE DE BRASÍLIA. Anuário Estatístico da Universidade de Brasília, 2020. Disponível em: https://laughing-hermann8aad29.netlify.app/geral.html\#popula $\% \mathrm{C} 3 \% \mathrm{~A} 7 \% \mathrm{C} 3 \% \mathrm{~A} 30-$ universit $\% \mathrm{C} 3 \% \mathrm{~A} 1$ ria-da-unb2015-a-2019. Acesso em: 01 fev. 2021.

Relatório de Gestão da Universidade de Brasília, 2019, p. 116-134, 2020a. Disponível em: http://www.dpo.unb.br/images/dpl/PUB RG2019 310820 v1 aprovadoCAD.pdf Acesso em: 08 out. 2020.

Secretaria de Comunicação da Universidade de Brasília. Disponível em: http://noticias.unb.br/76-institucional/4604-com-apoio-institucional-estudantes-seguemaprendendo-e-produzindo-conhecimento-durante-semestre-letivo-remoto. Acesso em: $04 \mathrm{fev}$. 2021.

Página eletrônica do Decanato de Planejamento, Orçamento e Avaliação Institucional. Disponível em: http://www.dpo.unb.br/images/phocadownload/dor/ACAO 4002 SIC.pdf Acesso em: 19 jun. 2020.

Página eletrônica da Diretoria de Desenvolvimento Social. Disponível em: http://www.dds.dac.unb.br/index.php/editais-2. Acesso em: 20 jun. 2020. 